\title{
ANALYSIS OF LONG TERM CARE IN THE CONTEXT OF SOCIAL AND HEALTH SERVICES IN SOCIAL INSTITUTIONAL FACILITIES IN SLOVAKIA
}

\author{
Mário Ležovič \\ Department of Health Policy and Health Economy, Faculty of Public Health, Slovak Medical University, Slovakia
}

\begin{abstract}
SUMMARY
Objectives: Long-term care for people with chronic illnesses and disabilities present an urgent challenge around the world. Existing systems of care, which typically rely on unpaid family members, are not by themselves enough to meet growing demands. This analysis includes survey on the structure of services provided in selected social facilities in Slovakia.

Methods: The survey on structure of provided services includes social facilities providing services to the target groups involved in this analysis: Elderly people in retirement age; Disabled and chronically ill citizens in working age. For data collection from social facilities we used questionnaire method. The data were obtained from the managements of these facilities $(n=405)$.

Results: In social facilities, the age range of clients was 76-85 years (31\%); the length of stay of a patient in a social facility was in $36 \%$ patients 11 years and longer. The most frequently performed activities in employees were related to services and activities (31\%) and social care (30\%). For $52 \%$ social facilities is waiting time 1 year and longer. The length of stay of patient in social facilities is affected in $83 \%$ by combination of health and social problems and as to the diagnosis structure the most prevalent conditions are ischemic heart diseases, heart attack, hypertension (39\%), locomotor disease (36\%). In 2006 the budget resources of social facilities were in $72 \%$ contributions from the state budget.

Conclusion: Long-term care is closely interlinked with other programmes and systems, which can reduce the need for long-term care or which complement it.
\end{abstract}

Key words: elderly people, chronically ill, long term care, social care, health care, health services

Address for correspondence: M. Ležovič, Department of Health Policy and Health Economy, Faculty of Public Health, Slovak Medical University, Limbová 12, 83303 Bratislava 37, Slovakia. E-mail: mario.lezovic@szu.sk

\section{INTRODUCTION}

Throughout the developed world, numbers and proportions of elderly people are growing rapidly (1). The aging population is currently one of the main issues facing international health care systems. It is a recognized fact that with advancing age, the likelihood of developing health problems and chronic disease will increase and the demand for health care resources will escalate. This will impact hospitals and long-term care facilities (2). In industrialized societies, the ageing process represents one of the major public health concerns, both for ensuring an adequate level of care to satisfy today's needs as well as for ensuring the system's sustainability in the near future (3). The high costs of treating chronic diseases suggest that reducing their prevalence would improve Medicare's financial stability. The formulation of policies needs to reflect these countries' unique conditions (4).

Individuals need long-term care (LTC) due to disability, chronic condition, trauma or illness, which limit their ability to carry out their daily basic self care or personal tasks. Long-term care refers to the provision of services for persons of all ages who have long-term functional dependency (5-10). This analysis includes survey on the structure of services provided in selected social care facilities.

\section{METHODS}

The survey on structure of provided services includes social facilities providing services to the target groups involved in this analysis: Elderly people in retirement age; Disabled and chronically ill citizens in working age. On the basis of the "target group" criterion the questionnaires were sent to Providers of social services: Retirement homes or retirement homes in combination with social service homes; Selected personal care service facilities and Social service homes for disabled adults: mental, physical, sensory or combined impairment. For data collection from social facilities we use questionnaire method. The data was obtained from the managements of these facilities which total 405 in Slovakia. The register of social facilities was acquired from The Ministry of Labour, Social Affairs and Family of the Slovak Republic (valid as of January 2007). 


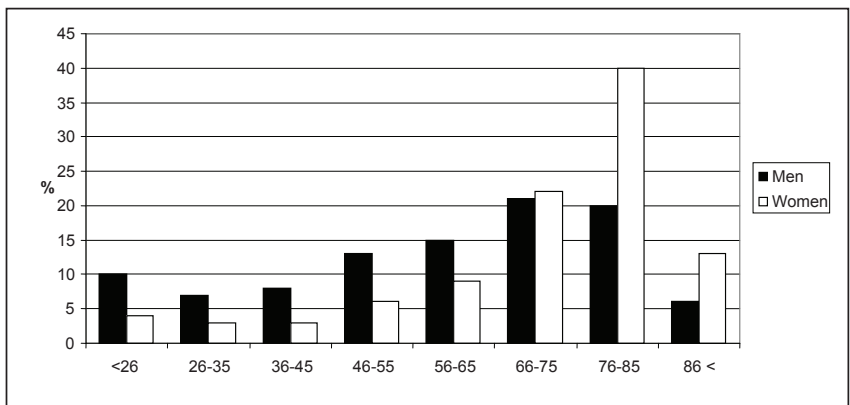

Fig. 1. The age structure of clients in social care facilities in Slovakia, 2007.

\section{RESULTS}

\section{The Conception of Social and Long-term Care as Envisaged by the Social Service Providers}

The return rate of questionnaires was very high. All in all, 307 (76\%) questionnaires from social facilities were returned. Basic client data - age structure of clients is as follows (Fig. 1):

First of all, it must be said that completed questionnaires and particularly the comments given at the end of questionnaires have shown that the levels of comprehension of the problem under analysis are different in the social sphere and in the health care sphere. Social facilities providing social services did not encounter any problems identifying health care activities in their facilities. There are two reasons for this:

- In social facilities there is a large number of medical nurses, who are acquainted with the Therapeutic Order and the services listed it.

- The social sector has been trying for some time to find a way to achieve reimbursement of health care services from the health insurance companies. In 2001 selected social facilities simulated classification of health care services, according to the Therapeutic Order in a one month period, so management of these facilities has actual experience in this area.

Health care practitioners often declare that health care facilities must provide their clients with social care due to a lack of social services. However, few people in health care facilities are acquainted with the Act on Social Assistance and with specific social care activities. To avoid potential misunderstandings in the introductory part of the questionnaire we defined a "social bed in the health care facility" in several ways. We asked all respondents involved to mark how they did understand the term.

The question was: So called "social" beds or social clients, who are a burden to health care sector, are often mentioned. What is a social bed/client in your facility?

1. A client who is no longer in need of in-patient healthcare, but no social service or facility is available where he/she could be transferred on completion of treatment.

2. A client whose condition does not necessarily require admission to our facility, however, he/she requires long term care and there isn't anybody to take care of him/her.

3. Basically all of our clients who on completion of treatment cannot move to the care of out patient physician due to a lack
Table 1. Variants of identification of "social bed" in Slovakia 2007

\begin{tabular}{|l|l|}
\hline & $\%$ \\
\hline There is no place to go on completion of treatment & 31 \\
\hline Was admitted, no place anywhere else & 46 \\
\hline No supporting services, must stay & 22 \\
\hline Other reasons & 17 \\
\hline
\end{tabular}

Table 2. Distribution of social facilities by proportion of clients provided with healthcare, Slovakia, 2007

\begin{tabular}{|l|c|}
\hline Proportion of clients provided with health care & $\%$ \\
\hline $10-24 \%$ of clients & 8 \\
\hline $25-49 \%$ of clients & 9 \\
\hline $50-74 \%$ of clients & 13 \\
\hline $75-95 \%$ of clients & 28 \\
\hline $96-100 \%$ of clients & 42 \\
\hline
\end{tabular}

Table 3. Distribution of employees of social facilities by the performed activities (not by education or qualification) in Slovakia, 2007

\begin{tabular}{|l|l|l|l|}
\hline $\begin{array}{l}\text { Health care } \\
\text { nursing }\end{array}$ & $\begin{array}{l}\text { Social } \\
\text { care }\end{array}$ & $\begin{array}{l}\text { Other professional } \\
\text { activities in the area of } \\
\text { social services }\end{array}$ & $\begin{array}{l}\text { Related services } \\
\text { and activities }\end{array}$ \\
\hline $24 \%$ & $30 \%$ & $15 \%$ & $31 \%$ \\
\hline
\end{tabular}

of supporting social services and therefore they have to stay with us.

4. Other (specify)

This question was answered by 236 out of 307 social facilities. The structure of answer is as follows (Table 1):

\section{Health Performances in Social Facilities}

182 out of 260 social facilities (70\%) reported that all or almost all of their clients also needed health care. In general it may be said that facilities for elderly people provide health care to at least a quarter of their clients. Other social care facilities within our sample generally provide health care to all of their clients (Table 2). A small portion of these facilities provides health care only to a specific part of their clients.

The task of identifying the structure of individual activities of the facility by the activities of individual employees proved impossible to complete (Table 3). For social services we tracked the following structure of activities by asking:

Try to assign employees of your institution by the performed activities (not to by education or qualification) to these four groups:

1. Health care nursing: physicians, nursing staffs.

2. Social care: employees perform direct utility activities, mainly routine, simple daily activities, help with personal hygiene and support self-sufficiency in individual life activities, provide assistance in creating basic social and societal contacts, and support social integration of clients.

3. Other professional activities in the area of social services: pedagogic, psychological, medico-pedagogical, pastoral, economic and managerial. 
4. Related services and activities: boarding, lodging, cleaning, transportation, maintenance.

Related services and activities (boarding, lodging, cleaning, transportation and maintenance) are also distinctly defined. From all facilities reported related activities and services amounting to more than $30 \%$ of all work performed, social care and health care nursing to $30 \%$ and $24 \%$, respectively.

Data on the scope of social care, health care and other professional activities are rather ambiguous and do not allow for content interpretation. These data reflect the confusion dominating the area of social services provision. At the same time, they document the acute need for social services reform. In the past, social care provision was based on biological-medical approach in care for the elderly and the disabled. This was reflected in the high number of medical nurses who were employed to provide clients with this type of care. On the adoption of new acts on health care and financing, social facilities are not authorized to provide health care by their own employees. New rules in health care sector were also reflected in Act No. 448/2008 Coll. on Social Assistance which states that social facilities only ensure health care provision (i.e. they do not have to provide it directly). Nevertheless, medical nurses, and later nurses, in social facilities continue providing nursing services. As a result, the entry of data on the scope of social care and other professional activities is rather chaotic. Some facilities classify the work of medical nurses as activities in the area of social care, others distinguish between personal care activities and nursing activities and the third group classifies the work of medical nurses as nursing activities even though they do know they are not authorised to perform such activities.

When we asked what healthcare performances according to the Therapeutic Order were provided by qualified health care employees to the clients of the social facility, we received very qualified answers.

The most often performed services were:

- Care of a client with a permanent catheter

- Positioning of patient after 8 hours

- Purgatory clyster

- Continual monitoring of client's clinical state - measurement of blood pressure, pulse, respiration, body temperature, intake and output of fluids

- Monitoring of other functions according to the physician's order

- Measurement of blood pressure, body temperature, pulse, respiration

- Monitoring of diuresis

- Application of medicaments i.m., s.c., i.c., i.v.

- Nursing care focused on decubitus prevention

- Re-bandaging, cleaning and/or removal of stitches

- Nursing rehabilitation

- Urine testing using reagent strips

- Taking of body fluids, rectal smear, taking sputum samples

- Provision of pre-medical aid in life-threatening states

The answer to the question whether the facility calculated potential income for health care that was provided from insurance companies gives further information on health care in social facilities. This was done by 14 social facilities (5\%), but only 12 facilities of these facilities provided specific data. According to
Table 4. The composition of receipts in facility (without the resources earmarked for capital outlay) by sources in 2006 , Slovakia

\begin{tabular}{|l|c|}
\hline & Average \\
\hline Contributions from the State budget & $72 \%$ \\
\hline Clients' payments for services provided & $26 \%$ \\
\hline Earnings of the facility & $3 \%$ \\
\hline Donations and grants & $2 \%$ \\
\hline Other & $1 \%$ \\
\hline
\end{tabular}

Table 5. The reasons for stay in social facilities in Slovakia, 2007

\begin{tabular}{|l|c|}
\hline Health problems & $11 \%$ \\
\hline Complication of basic disease & $8 \%$ \\
\hline Combination of health and social problems & $83 \%$ \\
\hline Social problems & $15 \%$ \\
\hline
\end{tabular}

Table 6. The diagnostic composition of clients in social services homes in Slovakia, 2007

\begin{tabular}{|l|c|}
\hline & Average (\%) \\
\hline Sudden cerebrovascular accident & 14 \\
\hline Diabetes mellitus & 18 \\
\hline Ischemic heart disease, coronary thrombosis, hypertension & 39 \\
\hline Locomotor diseases & 36 \\
\hline Alcoholism & 7 \\
\hline Senile dementia & 20 \\
\hline Alzheimer disease & 7 \\
\hline Schizophrenia & 8 \\
\hline Psychosis & 10 \\
\hline Mental disability & 27 \\
\hline
\end{tabular}

the calculations of the 12 facilities, the potential income from insurance companies for health care provided would amount to almost 30\% of total costs in these facilities (weighted average).

The last question in this series concerned the preferred format of payment for health care. More than a half of social facilities (63\%) prefers combined payment for services and by diagnosis. $10 \%$ prefer payment for services and $26 \%$ prefer payment by diagnoses. $2 \%$ facilities prefer other formats of payments.

The proportion of individual resources of receipts in social care facilities (without the resources earmarked for capital outlay) by sources in 2006 was as follows (Table 4):

The following (Table 5) sums up the reasons for their stays in social facilities, and the next (Fig. 2) shows that more than three quarters of these patients (89\%) stay in the social care facility for several years.

In social services homes for adult citizens there are clients with various diseases as well as clients that cannot be placed anywhere else. Co-existence of these various groups of clients in one facility causes often conflicts among clients or between clients and employees. The diagnostic composition of clients in social services homes for adult is reported as follows (Table 6): 


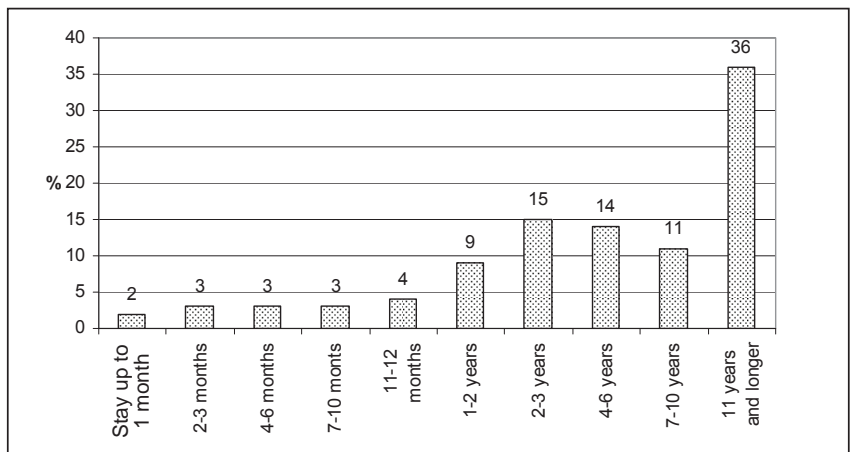

Fig. 2. The length of stay of a client in social care facilities in Slovakia, 2007.

\section{DISCUSSION}

Long-term care is closely interlinked with other programmes and systems, which can reduce the need for long-term care or which complement it. Initially, long-term care policies were formulated as a response to ageing of the population, which brought about growing needs of elderly people for social care and health care, and was associated with relatively rapid increases of necessary costs (11). Old people are now the most rapidly growing segment of the population (12), and represent $20 \%$ of all Slovak inhabitants (11). An important additional consequence of population aging is the increasing needs and costs of long-term care (12).

Co-morbidity has an additional impact on disability as well as on the use of medical care and long-term care. The general impact of chronic conditions is described by calculating healthy life expectancies and assessing the loss of healthy life resulting from chronic morbidity, disability and long-term care (13). As the public expenditure on long-term care is likely to increase with the ageing of the population, a better understanding of the factors related to long-term care institutional care is of particular interest. Several population-based prospective studies have shown that functional disability and cognitive impairment are associated with institutionalization, but systematic evidence on the effects of different chronic diseases on institutionalization is scarce (14).

There is no single solution to the problem of integration of the health and social care components of long-term care. Consolidation and decentralisation of administrative functions represents an important integration strategy. There are various models of organising and providing services that can bring services together "under one roof", and whatever model is selected, some form of case - management is usually necessary to ensure that services target the at-risk population (11). The respective public administration bodies - the Ministry of Labour, Social Affairs and Family, self-governing regions - and social service providers expect that legislation and organisational issues connected with financing health services in social service facilities by health insurance companies will be solved. They expect subsequent increase in financial resources in this area. At the moment, public administration and social service providers are not able to specify exactly all the obligations they will have to take over with respect to long-term care. At this time nobody in the social or health care area is concerned with the question of long-term management of the citizen who is provided social and long-term care. It is hard to estimate the scope and financial representation of health services executed in social facilities, as they do not pertain to all social care facilities.

In general it can be stated that the high degree of readiness of both sectors to prepare and implement an integrated model of social and long-term care does not stem from the adoption of a holistic approach to the human being in Slovakia; rather it means that an improvement of financial situation of both is expected. The social sector needs to resolve resources in order to extend the supply of services which are still in short supply. The health sector, on the contrary, needs to take another step towards the rationalization and reduction of the supply of in-patient healthcare.

There are at least three reasons for creating an integrated model of long-term care and recognize it as a new public service for citizens:

1. The current organisation of providing and financing the health care and social support to individuals with long-term functional disabilities is non-transparent, uncoordinated, and of low quality and effectiveness. Such an ineffective system poses barriers to the implementation of health system reform, and as a consequence, appropriate correction measures will not achieve the desired solutions for the population.

2. The existing system of health care and social support in terms of accessibility and service quality is insufficient to satisfy current demand and cannot meet future growth in demand for long-term care due to rapid aging of the population and increasing requirements of severely handicapped citizens.

3. Following the decentralisation of powers to regional and local governments, from 2002, and decentralisation of financing from 2005, the authority for coordination and responsibility for public services for citizens on nation-wide, regional, and local level becomes a most critical question.

Key factors enabling and obstructing advances in public health include overall macroeconomic and social conditions, lack of multisectoral collaboration, and better consideration of policy options (15).

\section{CONCLUSION}

Long-term care within the public services system does not exist in Slovakia.

The long-term care model will provide the foundation for legislation and associated regulation of the new system. The goal of the long-term care legislation will be:

- to define material, organisational, and financial aspects of the service system, aids, and benefits that will integrate health and social care, aids, and other supportive tools necessary for provision of essential support to individuals suffering from long-term functional disabilities, a system that would focus on improving their quality of life as well as the quality of life of their families who render much needed care and support;

- to guarantee effective accessibility to long-term care for citizens and concurrently to define the conditions for financial sustainability and efficiency of the system;

- to interconnect the formal system of long-term care provision with informal support of families and relatives in the most efficacious manner. 


\section{REFERENCES}

1. Noro AM, Häkkinen UT, Laitinen OJ. Determinants of health service use and expenditure among the elderly Finnish population. Eur J Public Health. 1999;9(3):174-80.

2. Lovell M. Caring for the elderly: changing perceptions and attitudes. J Vasc Nurs. 2006 Mar;24(1):22-6

3. Larizgoitia I. Evaluating long-term care: approaches to evaluating LTC systems. In: Brodsky J, Habib J, Hirschfeld MJ, editors. Key policy issues in long-term care. Geneva: WHO; 2003. p. 227-42.

4. Lezovic M, Dzundova Z, Kovac R, Raucinova M. Long-term care as an urgent challenge. Bratisl Lek Listy. 2007;108(3):161-2.

5. World Health Organization. Current and future long-term care needs. Geneva: who; 2002.

6. Organisation for Economic Co-operation and Development. Projecting OECD health and long-term care expenditures: what are the main drivers? Economics Department Working Papers no. 477. Paris: OECD; 2006.

7. Lezovic M, Kovac R. Comparison of long-term care in European developed countries to possible implementation in Slovakia. Bratisl Lek Listy. 2008;109(1):20-4.

8. Organisation for Economic Co-operation and Development. Long-term care for older people. Paris: OECD; 2005
9. Brodsky J, Habib J, Hirschfeld MJ. Key policy issues in long-term care. Geneva: WHO; 2003.

10. Brodsky J, Habib J, Mizrahi I. Long-term care laws in five developed countries: a review. Geneva: WHO; 2000.

11. Lezovic M, Raucinová M, Kovác A, Moricová S, Kovác R. Long-term care in developed countries and recommendations for Slovak Republic. Cent Eur J Public Health. 2008 Mar;16(1):21-5.

12. Topinková E. Health care services for the elderly in Czech Republic: new trends and future development. Cent Eur J Public Health. 1994 Dec;2(2):118-21.

13. Van den Bos GA. The burden of chronic diseases in terms of disability, use of health care and healthy life expectancies. Eur J Public Health. 1995;5(1):29-34.

14. Nihtilä EK, Martikainen PT, Koskinen SV, Reunanen AR, Noro AM, Häkkinen UT. Chronic conditions and the risk of long-term institutionalization among older people. Eur J Public Health. 2008 Feb;18(1):77-84.

15. Gulis G, Korcova J, Letanovsky P, Marcinkova D. Transition and public health in the Slovak Republic. BMJ. 2005 Jul 23;331(7510):213-5.

Received October 24, 2008 Accepted in revised form March 30, 2009 